\title{
Ideographic Experiences in Raising Dyslexic
}

\author{
Noor Amiera Alias, Akehsan Dahlan \\ Occupational Performance and Behaviour Measurement Group (RIG), Occupational Therapy Department, Faculty \\ of Health Sciences / CORE Huminities and Quality of Life, Universiti Teknologi MARA, Kampus Puncak Alam, \\ 42300 Selangor, Malaysia \\ nooramiera@puncakalam.uitm.edu.my
}

\begin{abstract}
The aim of the study is to illuminate the challenges that mothers experience in raising children with dyslexia. A semi-structured interview was conducted with ten mothers of children with dyslexia at the Dyslexia Association Malaysia (DAM) centre. Data were analysed using Interpretative Phenomenological Analysis (IPA) approach. Two main themes emerged from the interview transcripts, i.e. "difficult yet enduring" and "self-perseverance". The current study revealed challenges of mothers with dyslexic children, which could be addressed by health professionals. In addition, this study provides insights and a deeper understanding for health professionals to support mothers and families who have children with dyslexia.
\end{abstract}

Keywords: Dyslexia, Experience, Mothers, Interpretative Phenomenological Analysis

eISSN: 2398-4279 @ 2017. The Authors. Published for AMER ABRA by e-International Publishing House, Ltd., UK. This is an open access article under the CC BY-NC-ND license (http://creativecommons.org/licenses/by-ncnd/4.0/). Peer-review under responsibility of AMER (Association of Malaysian Environment-Behaviour Researchers), ABRA (Association of Behavioural Researchers on Asians) and cE-Bs (Centre for EnvironmentBehaviour Studies), Faculty of Architecture, Planning \& Surveying, UniversitiTeknologi MARA, Malaysia.

https://doi.org/10.21834/ajqol.v2i7.59 


\subsection{Introduction}

Dyslexia is a word that comes from Ancient Greek, 'dys', which means 'difficulty with' and 'lexis', meaning 'words'. Children with dyslexia face difficulties either in reading, spelling or writing (Lemperou, Chostelidou \& Griva, 2011). Dyslexia is one of the main subtypes of Specific Learning Disability (SLD) (Lam, 2005), which is characterized by difficulties in recognizing words accurately, difficulties in spelling, reading writings and decoding abilities despite having integral cognitive abilities, senses of hearing and vision ( Lyon, Shaywitz, \& Shaywitz, 2003; Karande, et al., 2009). These difficulties often lead to poor academic performance and are often being misunderstood as, for example, being lazy and easily giving up, hence are often subjected to punishment (Oga \& Fatimah, 2012).

The prevalence of children diagnosed as dyslexia in the United States (US) is about 15 percent from the children population who have learning disabilities (Karande \& Kulkarni, 2009), while in Hong Kong, the incidence of dyslexia is about 10 percent from the population (Chan, 2008). In addition, about 314,000 students are estimated to have dyslexia in Malaysia (Oga \& Fatimah, 2012). This report is consistent with a report by Siti Huzaimah and Aiza (2012), which indicated that there are many students in primary school who are placed in remedial classes that are meant for students with learning difficulties. It is believed that the prevalence of children with dyslexia is expected to increase from year to year.

In Malaysia, there are many clinics and private centers that do not provide rehabilitative services to children with dyslexia. Existing centers are not sufficient to support the large number of this increasing population. Furthermore, there are many parents and teachers who still have insufficient knowledge and are unaware about dyslexia and are not exposed to the conditions (Siti Huzaimah Sahari \& Aiza Johari, 2012). As a result, many children with dyslexia are delayed in receiving their remedial education or extra classes, which are provided by special educators.

This present study focuses on mothers' experience in raising children with dyslexia as understanding the experience is essential to help the children, as well as to provide support to the mothers (Lemperou et al., 2011). Furthermore, it is postulated that understanding the experience of mothers of children with dyslexia will facilitate and enhance their quality of life.

\subsection{Literature Review}

Previous studies indicated that there are several issues experienced by mothers with dyslexic children. Mothers are often associated with having negative feelings such as denial, frustration, guilt and stress when an aspiration to have a 'perfect' child is unfulfilled (Chandramuki, Venkatakrishnashastry, \& Vranda, 2012). The mothers are often disappointed when their children failed to meet their high expectation. About 95 percent of mothers of children with dyslexia are experiencing anxiety regarding the child's future life and their academic performance (Karande, et al., 2009). 
Furthermore, they are also concerned with the child's inappropriate behavior, which may affect their self-esteem and pattern of socialization with peers (Karande, et al., 2009). These issues increase motherhood experiences that subsequently give negative effects to mothers' life, such as fatigue, lack of sleep and poor sleep quality, as well as changes in daily routine, loss of appetite and weight loss (Chien \& Lee, 2013).

To date, there are limited studies concerning the experience of Malaysian mothers in raising children with dyslexia. Therefore, this study aims to unfold and illuminate the challenges that they experience in raising children with dyslexia.

\subsection{Methodology}

This current study is qualitative in nature, and it attempts to provide an exploration of one's life experiences in raising children with dyslexia. It was conducted using a phenomenology approach as it is well-suited with the objectives of this study to elicit further details and to understand people's life experiences (Smith, Flowers \& Larkin, 2009). The participants were recruited using convenience sampling of ten mothers who have a child diagnosed with dyslexia. They held a caring role for children aged between 7 to 12 years old. The interview was carried out in the form of semi-structured interview at the Dyslexia Association Malaysia (DAM). The participants came from different ages, which range between 30 to 43 years old. They are also different in terms of their education level, personal background and duration of caregiving to the children. This is an endeavor to explore a diverse variety of their unique experiences in raising children at different stages of dyslexia.

The semi-structured interview was conducted using an interview guide which consists of open-ended questions. The researchers designed the interview guide according to KAWA's model (Iwama, Thomson, \& Macdonald, 2009). Once the mothers have consented, they were interviewed by an interviewer for approximately 45 minutes to one hour. All conversations were recorded throughout the interview session using an audio recording device. The recorded interviews were subsequently transcribed verbatim. The transcripts were closely analyzed using the six steps of Interpretative Phenomenological Analysis (IPA) as described by Smith et al. (2009).mean differences were identified based on Cohen's effect size (Cohen, 1988).

\subsection{Results and Discussions}

The findings presented using IPA revealed two superordinate themes, each with varying numbers of subthemes. Superordinate themes and subthemes of challenges of mothers in raising children with dyslexia emerged are summarized in Table 1. 
Table 1. Superordinate and subthemes emerged from the interview transcripts.

\begin{tabular}{ll}
\hline Superordinate Themes & Subthemes \\
\hline "Difficult yet enduring" & Time constraints \\
& Lack of knowledge \\
& Increased financial demand \\
& School issues \\
& Negative feeling towards child's condition \\
& High demand in role as a mother \\
"Self - perseverance" & Changes in life pattern \\
&
\end{tabular}

The participants in this study expressed two superordinate themes and a number of subthemes. These themes represent and illustrate a variety of underlying ideographic experiences, which are further detailed with quotes from the interviews.

\subsection{Theme 1:"Difficult yet enduring"}

Most of the mothers expressed that they had time constraint in managing their children with dyslexia. At the same time, the children with dyslexia need extra time and assistance to finish their homework. This is illustrated by a 34-year-old mother of a child with dyslexia. She said:

"Sometimes, I teach him. But, when I'm at home, there is only a few hours left before he goes to sleep. He needs more time to do his homework because he does not understand. So I need more time. Only during weekends I try to find time to sit and teach him."

On the other hand, they also have a lack of knowledge about dyslexia. Most of them do not know how to teach their children in the correct way. As illustrated by a mother:

"We don't know how to teach them...I don't know what else that I can do to help my son...I just have to tolerate with whatever problems he creates."

The mothers also send their children for extra classes such as tuition, piano, music and other classes that would help their children to learn effectively. The mothers reflected that they spend a lot of money to pay fees for the extra classes, travelling cost that includes toll and petrol, and other educational materials such as whiteboards and flash cards to help the children at home. It has become a burden when the fee of extra classes is increasing. This is illustrated by a working mother who has a seven-year-old child with dyslexia. She said:

"We don't know how to teach, so we send out to help him... because everything is not cheap. The school fee is not expensive. But it is because we stay so far. So the petrol is more than the school fees in the end...send him to a special class....all the additional classes like music class definitely cost a lot."

Another challenge in raising their child with dyslexia is related to issues at school. This is illustrated by one of the mothers. She stressed: 
"Like my son, he has a trauma to read maybe because his teacher doesn't know how to handle a dyslexic child. They might talk too loudly to my son. So, it affects my son whereby he refused to read at all, and it is difficult for me to encourage him to read."

Most of the mothers also have negative feelings towards the child's condition, such as low self-esteem, guilt, self-blaming, feeling sad, denial, worry and disappointed. They have low self-esteem when other people compare the achievement of their children to other children in the same age. At the same time, some of them described that they feel guilty when they have to see their child struggling in doing their homework as well as attending extra classes. In early stages, most of the mothers were in denial of their children's condition because they perceived that their children were 'normal'. Nevertheless, they accepted the situation after conversations with medical professionals, family members as well as praying to God. One of the mothers showed how she initially denied her dyslexic child's condition:

"Teachers complained that my son is too slow...one day I see that my son write words incorrectly ' $p$ ' and ' $b$ '....my husband said he looked like dyslexic child...I said no...impossible. He is an intelligent boy...he has a good memory and talkative ...Then after being diagnosed, I have to accept it..."

Most of the mothers feel very sad and disappointed when they expect a normal child, but apparently the child has dyslexia. In addition, they feel more depressed when they have received complained from teachers that their children are slower in reading and writing compared to other children in the same age. During the interview session, one of the mothers was crying when she described:

"I feel down when one of the tuition teachers told me that my son has no future and cannot be successful in his life...he cannot perform well in his future career... and he can only work at fast food restaurants...[crying]....when I think about this, I feel very sad."

\subsection{Theme 2: "Self-perseverance"}

As participants described their responsibilities of being a mother, they also need to face the demanding role as a mother to help their children. The mothers described that their husband had limited time with their children. This is illustrated by:

"It's very hard, because it is only me at home during the weekend. My husband is busy...By that time, I want to teach my son...I need to wash dishes, clean up the kitchen, wash clothes and others...Sometimes whenever I want to teach my son, his little sister comes to disturb... there are many things to do at the same time."

Some of the participants also explained that their daily life pattern is disturbed. Currently, the first thing that they do when coming home from work is sitting together with their dyslexic child. They also sacrificed their personal and social time such as shopping, going to the spa, hanging out with friends and others. This can be illustrated by the following quote: 
"Previously, when I got my paperwork, I just focus on my work...even at home I will finish my paperwork...Now... when I know that my son has dyslexia... left my paperwork aside...focus on him every morning from $8.30 \mathrm{am}$ until $10.30 \mathrm{am}$ without fail I will sit together with him to teach him...I help him to do his homework...because I believe at that time, his brain is still fresh to learn."

The present study sheds light on the challenges in the life experience of mothers with dyslexic children. Two superordinate themes emerged, namely "difficult yet enduring" relating to subthemes: time constraints, lack of knowledge, increasing financial demand, school issues and negative feeling towards the child's condition. Another superordinate theme is "self-perseverance" relating to subthemes: high demand of the role as a mother and changes in life pattern.

Time constraints is considered as one of the big challenges in raising children with dyslexia. This is because most of the participants are working mothers. Long working hours do not permit them to have sufficient time to help their children. They need longer durations to help their children who have difficulties in reading and understanding their homework. A previous study also revealed that parents spent long periods of time to help their dyslexic child every day (Chien \& Lee, 2013). Similarly, a study found that teachers who teach in higher level education have restricted time to help dyslexic students as they need to explain the instruction individually in verbal and written form (Olofsson, Ahl, \& Taube, 2012). So, the mothers have to find other solutions, such as altering their daily schedule or asking their spouse to assist them.

In spite of the urgency and willingness to assist their children, the mothers also have a lack of knowledge about dyslexia. They are not exposed to dyslexia due to lack of awareness regarding dyslexia (Oga \& Fatimah, 2012). The finding of the study also found that teachers misunderstood the child's problems and did not provide sufficient support as needed by the children. This could be due to lack of knowledge and awareness among teachers. As suggested by Lemperou et al. (2011), teachers should attend In-Services Education and Training (INSET) course to gain knowledge and provide learning adjustments as required to help dyslexic children. Teachers should be aware of the strategies or approaches that can help the children in the process of learning to contribute to more positive outcomes (Hanin Naziha, Zaiton, \& Norshidah, 2013). This provides strong evidence that teachers need to play an important role to help the children to improve themselves in an effective way.

Nevertheless, the finding from this study is inconsistent with another study that was conducted in Sweden. Olofsson and her colleagues found that teachers have taken appropriate action to support and facilitate students in the classroom (Olofsson et al., 2012). They are also aware that the course structure and correct teaching methods could accommodate their students with issues related to dyslexia. Related authorities in Malaysia should also adopt a similar approach. Health promotions that are aimed to expand the level of awareness and knowledge could be conducted, which subsequently will provide more educational and remedial opportunities for children with dyslexia. 
In addition, the increasing financial demands cannot be denied as the cost of living is rising from year to year. The mothers also need to continue working as financial issues emerge with the current demand (Nik Rosila \& Siew, 2010). In this study, mothers claimed that the increasing cost of travelling as well as price of materials have become a burden to their family. However, some of the mothers are willing to pay for the growth of their children if they can afford it. Despite this, the government and Ministry of Education need to consider improving facilities and offering more opportunities in providing remedial education especially in rural areas.

Another subtheme is negative feelings, such as sadness, denial, worry and others, which are common among mothers who have children with dyslexia. Denial is of the ways used to cope with unaccepted reality (Jenaabadi, 2014). Similar to a previous study, one of the reasons is high expectation towards children achievement (Chandramuki et al., 2012). Furthermore, some people such as teachers or friends who give incorrect assumptions and opinions without being sensitive to the mothers' feelings may initiate this negative feeling. Negative feelings affect the mothers in their social relationship, hence gives impact to their quality of life. It is suggested that the mothers should seek help from a health professional, for example, to have a counseling session to eliminate or minimize negative feelings (Chien \& Lee, 2013; Jenaabadi, 2014). As a result, the mothers will have more intrinsic motivation and improve their quality of life.

'Self-perseverance' themes emerge in this study when the mothers have high demand of roles and changes in life pattern. Mothers need to face multiple roles in their daily routine while they have to become more patient and tolerant towards children with inappropriate behavior. A child with such behavior requires a mother to give more attention and spend more time with her child. Malaysian mothers also believe that they are an important 'teacher' in teaching their children (Fauzilah, Choo, \& Manjet Kaur Mehar Singh, 2011). However, mothers, especially those who are working, also have to do household tasks and raise other children (Yeo \& Teo, 2013). Thus, they could find it even more difficult to carry out their roles wisely. As a result, children with dyslexia will be neglected and may have fewer opportunities to succeed. Moreover, it is more challenging when the mothers also need to change their life pattern by reducing their social activities and other activities. As dyslexia is a persistent condition, the mothers need to be better prepared mentally and physically in the future. Supports from spouses, families, friends and health professionals could help mothers to cope with their situations. Alternatively, it is more helpful if mothers can get involved in any support group, such as social network groups to share or exchange opinion with others who are in the same shoe.

As discussed above, the mothers undeniably need other people to assist them in facing those challenges and managing their dyslexic children. Besides, teachers as well as mothers play a role as a good facilitator and instructor while the children need to be prepared to have a successful learning ( Fauzilah et al., 2011; Fatimah, Norazzila, \& Rohani, 2013). 
The limitations of this study are limited to a population of mothers only. Therefore, it is suggested that further study in this area is conducted which may include fathers of dyslexic children as participants. This could give more in-depth perspectives in raising children with dyslexia.

\subsection{Conclusion}

This study contributes to the body of knowledge regarding dyslexia by presenting a detailed life experience and the challenges of mothers in raising their dyslexic children. The implication of this study highlights the need for mothers to be supported not only from their spouses, but also their friends, teachers and families as well as health professionals. Furthermore, the health professionals should consider those challenges in creating or planning effective programs and interventions for mothers with children with dyslexia in the future. In addition, this study has provided deeper understanding to the families, educational sector, the general public and health professionals, such as occupational therapists, to support mothers effectively.

\section{Acknowledgement}

The authors wish to thank the Faculty of Health Sciences, University Teknologi MARA (UiTM) and the Research Management Institute (RMI), UiTM. The authors would also like to acknowledge the President and staff at the Dyslexia Association Malaysia and mothers who have participated in this study. This research is supported by the Fundamental Research Grant Scheme (FRGS), Fasa 1/2012 (600-RMI/FRGS 5/3 (70/2012).

\section{References}

Chan, C. W. (2008). Overview of specific learning disabilities ( SLD )/ dyslexia developments over the last decade in Hong Kong. Hong Kong Journal of Paediatrics, 13(3), 196-202.

Chandramuki, D., Venkatakrishnashastry, I., \& Vranda, M. N. (2012). Attitudes of parents towards children with specific learning disabilities. Disability, CBR \& Inclusive Development, 23(1), 63-69.

Chien, W., \& Lee, I. Y. M. (2013). An exploratory study of parents ' perceived educational needs for parenting a child with learning disabilities. Asian Nursing Research, 7(1), 16-25.

Fatimah Ramli, Norazzila Shafie, \& Rohani Ahmad Tarmizi (2013). Exploring student's in-depth learning difficulties in mathematics through teachers' perspective. Procedia - Social and Behavioral Sciences, 97, 339-345.

Fauzilah Md Husain, Choo, J. C. S., \& Manjet Kaur Mehar Singh (2011). Malaysian mothers' beliefs in developing emergent literacy through reading. Procedia - Social and Behavioral Sciences, 29, 846-855. doi:10.1016/j.sbspro.2011.11.313. 
Hanin Naziha, Zaiton Ahmad, \& Norshidah Nordin (2013). The relationship between learning approaches and academic achievement among intec students, Uitm Shah Alam. Procedia - Social and Behavioral Sciences, 90, 178-186.

Iwama, M. K., Thomson, N. A., \& Macdonald, R. M. (2009). The Kawa model: the power of culturally responsive occupational therapy. Disability and Rehabilitation, 31, 1125-1135.

Jenaabadi, H. (2014). The study and comparison of stress levels and coping strategies in parents of exceptional (mentally retarded, blind and deaf) and normal children in Zahedan. Procedia - Social and Behavioral Sciences, $114,197-202$.

Karande, S., \& Kulkarni, S. (2009). Quality of life of parents of children with newly diagnosed specific learning disability. Journal of Postgraduate Medicine, 55(2), 97-103.

Karande, S., Kumbhare, N., Kulkarni, M., Shah, N. (2009). Anxiety levels in mothers of Children with specific learning disability. Journal of Postgraduate Medicine, 55(3), 165-170.

Lam, C. (2005). Services for developmental dyslexia in Hong Kong. Hong Kong Journal of Paediatrics, 10(2), 149152.

Lemperou, L., Chostelidou, D., \& Griva, E. (2011). Identifying the training needs of EFL teachers in teaching children with dyslexia. Procedia - Social and Behavioral Sciences, 15, 410-416.

Lyon, G. R., Shaywitz, S. E., \& Shaywitz, B. A. (2003). A definition of dyslexia. Annals of Dyslexia.

Nik Rosila Nik Yaacob, \& Siew, H. S. (2010). Mother working status and physical, aggressive behaviour among children in Malaysia. Procedia - Social and Behavioral Sciences, 5, 1061-1066.

Oga, C., \& Fatimah Haron (2012). Life experiences of individuals living with dyslexia in malaysia: a phenomenological study. Procedia - Social and Behavioral Sciences, 46, 1129-1133.

Olofsson, Å., Ahl, A., \& Taube, K. (2012). Learning and study strategies in university students with dyslexia: implications for teaching. Procedia - Social and Behavioral Sciences, 47(0), 1184-1193.

Siti Huzaimah Sahari, \& Aiza Johari (2012). Improvising reading classes and classroom environment for children with reading difficulties and dyslexia symptoms. Procedia - Social and Behavioral Sciences, 38, 100-107.

Smith, J. A., Flowers, P., \& Larkin, M. (2009). Interpretative phenomenological analysis: Theory, method and research. London: Sage, (Chapter 5 \& 6).

Yeo, K. J., \& Teo, S. L. (2013). Child behavior and parenting stress between employed mothers and at home mothers of preschool children. Procedia - Social and Behavioral Sciences, 90, 895-903 